\title{
INTRODUCTION OF COMPUTERS IN EDUCATION: STATE OF THE ART IN EIGHT COUNTRIES
}

\author{
TJeerd Plomp and Willem J. Pelgrum \\ Department of Education, University of Twente, Enschede, The Netherlands
}

(Received 11 July 1990; accepted in revised form 16 May 1991)

\begin{abstract}
In 1989, the IEA Computers in Education study collected data on computer use in elementary, lower- and upper secondary education in 22 countries. This paper presents some preliminary results for lower secondary education in Belgium-Flemish, Belgium-French, France, Greece, Japan, Luxembourg, The Netherlands, Switzerland and the U.S.A.

The major questions that are addressed are related to the availability and the use of hard- and software, the problems experienced in introducing computers in schools and the attitudes of the principals towards computers. The results show that the number of schools equipped with computers and the number of computers available in schools increased dramatically over the past few years. Despite this fact, computers still are only used by a limited number of teachers, and mainly for teaching students about computers; the integration of computers in existing subjects is still limited. The major problems experienced in educational practice are the lack of sufficient software of high quality and insufficiently trained teachers.
\end{abstract}

\section{INTRODUCTION}

The 1980s have shown a rapid increase in the use of information technology in most societies. The idea that computers are playing an important role in the life of every citizen is no longer disputed. However, how education should react to these developments and what role computers can and should play in schools is still an issue. Several perspectives on the rolc of computers in cducation exist, as well as many claims on the potential power of computers as instructional aids.

Many countries have adopted policies for the systematic introduction of computers in education. However, the major question still is: how should new information technologies be introduced in education and to what degree are the expected effects of policies actually realized in educational practicc?

The major goal of the Computers in Education study (Comped) of the International Association for the Evaluation of Educational Achievement (IEA) is to collect longitudinal and cross-national comparative data in order to contribute to the evaluation of policies on the introduction of computers in the countries that are participating in the project.

This paper will mainly focus on lower secondary schools. We will give a description of the design of the study and will show some preliminary results and trends for the following educational systems: Belgium-Flemish, Belgium-French, France, Greece, Japan, Luxembourg, The Netherlands, Switzerland and the U.S.A. Moreover, the results presented will be mainly limited to those schools that are using computers for instructional purposes and to data on school level provided by principals and computer coordinators.

\section{THEORETICAL BACKGROUND}

Education is a complex system, consisting of subsystems at different levels: at the macro level the educational system of a country or state, at the meso level the school and the classroom, and at the micro level the student. On each level, educational decisions are influenced by different actors; for example, at the school level the school board, the principal, the subject matter department, and the teacher. External influences may be exerted by, for example, business and industry, or parents. The output of a subsystem at a certain level can be conceived as the input for the subsystem on the next level. For example, the output at the macro level is the intentions and the plans of governments, laid down in official documents, or existing shared conceptions of what is expected from schools. Taking this as the input at the school level, the output consists of the activities and 
the practices in the classrooms, and the teachers time allocations and instructional practices with computers. This is the input at the micro level, resulting in cognitive skills and attitudes of students.

When considering the domain of computers in education, we recognize that it is in a constant state of flux. There are many pressures for the acceptance and incorporation of computers at all levels of education, which exert a continuous influence upon what happens in the schools. Therefore, the study of computers in education is also a study of educational change in action. The literature on educational change (for example, [1] and [2]) suggests that a relatively small number of factors are influencing how the different system levels influence each other, and how on a certain system level the desired output might be attained. These factors include the quality, clarity and relevance of the objectives and the characteristics of the innovation (content, materials, instructional strategies); support and leadership; staff development; experiences with innovations; and evaluation and feedback.

\section{THE DESIGN OF THE STUDY}

The study consists of two stages. The first stage (1987-1990) is meant to give a description of computer use by collecting data on school- and teacher level. The second stage of the study (1990-1994) is intended (1) to replicate measures collected in the first stage in order to study developments over time and (2) to collect data on student level in order to assess the effects of using computers. As this paper focuses on part of the data collected in stage I, we will give here only a description of the design issues involved in that stage.

\section{Populations and samples}

In general, the populations of interest for this study are located in primary, lower secondary and higher secondary eduction. Although the data collection in stage I was confined to the level of schools and teachers, the longitudinal character of the study required that the populations are defined in terms of student characteristics. The definitions are such that they match as closely as possible the definitions which were used in earlier IEA studies. For Comped the following population definitions are proposed for stage II:

Population I: students in the grade in which the modal age is $10 \mathrm{yr}$ (if more than one grade has a modal age of $10 \mathrm{yr}$, the grade with the largest number of $10 \mathrm{yr}$ olds should be taken)

Population II: students in the grade in which the modal age is $13 \mathrm{yr}$ (if more than one grade has a modal age of $13 \mathrm{yr}$, the grade with the largest number of $13 \mathrm{yr}$ olds should be taken)

Population III: students in the final year of secondary education

The data collection at school and teacher level in stage I was aimed at grade levels which correspond with these definitions, plus and minus $1 \mathrm{yr}$ for population I and II, and minus $1 \mathrm{yr}$ for population III.

Table 1 shows the sizes of the samples of lower secondary schools that were drawn in each of the educational systems considered in this paper.

In most countries the sample of computer-using schools is sufficiently large to obtain good national statistics. In Greece, the number of such schools is small, and comprises all schools using

Table 1. Sample sizes of population II schools per educational system. Data are numbers of schools in each category

\begin{tabular}{lcccc}
\hline & \multicolumn{3}{c}{ Sample } & \\
\cline { 2 - 4 } System & Users & Non-users & Not defined & Population \\
\hline Belgium-Flemish & 229 & 61 & 8 & 827 \\
Belgium-French & 190 & 40 & 0 & 759 \\
France & 439 & 6 & 3 & 4825 \\
Greece & 69 & 317 & 52 & 1618 \\
Japan & 254 & 87 & 36 & 11,131 \\
Luxembourg & 27 & & & 32 \\
The Netherlands & 280 & 18 & 5 & 2337 \\
Switzerland & 709 & 283 & 38 & 1537 \\
U.S.A. & 382 & 3 & 40 & 38,329 \\
\hline
\end{tabular}


Table 2. Available instruments for each student population

\begin{tabular}{lll}
\hline Population & \multicolumn{1}{c}{ Instrument } & \multicolumn{1}{c}{ Respondent } \\
\hline All & National questionnaire & National research coordinator \\
I & School questionnaire & Principal \\
Modal age 10 & $\begin{array}{l}\text { Technical questionnaire } \\
\text { Teacher questionnaire }\end{array}$ & $\begin{array}{l}\text { Technical person } \\
\text { Teacher grade } 46\end{array}$ \\
II & School questionnaire & Principal \\
Modal age 13 & Technical questionnaire & Technical person \\
& Teacher questionnaire subject* & Subject teacher grade 8 \\
III & Comped questionnaire & Teacher grade 7-9 \\
Final year of & School questionnaire† & Principal \\
secondary & Technical questionnaire $†$ & Technical person \\
education & Comped questionnaire & Subject teacher final grade \\
\hline
\end{tabular}

*Subjects are: mathematics, science and mother tongue.

†Probably in most countries integrated with population II version.

computers in lower secondary education. In Luxembourg, all secondary schools are participating in the study.

As the schools sampled in each country were drawn with unequal probabilities, all statistics reported are weighted according to the inverse of the selection probabilities for each case.

\section{Instruments}

Table 2 contains an overview of all instruments used in stage I of the study. It should be noted that the teacher questionnaires for the three existing subjects have the same content except for the specification of the subject area in many questions about computer use.

As indicated above, the results presented in this paper are derived from the School and Technical questionnaire for population II (lower secondary schools).

\section{RESULTS}

In this section for nine educational systems, some results of the Comped study for lower secondary education will be presented. Pelgrum and Plomp [3] present the first results from all participating countries. The number of countries per figure or table may differ, depending on the availability of cleaned data at the time of the writing of this paper.

\section{The availability of basic computer materials}

The availability of hard- and software is an important necessary condition for the introduction of computers in education. We therefore will first describe the availability of these materials and present some indications of the quality.

\section{Hardware}

Table 3 shows that in 1989 the percentages of schools using computers for instructional purposes varies across the countries from 5 to $100 \%$. The percentage in Greece is reflecting that this country has only a special project in which a limited number of schools is involved.

Table 3. Average numbers of computers in junior secondary schools and the percent of schools using components, in cach country/system

\begin{tabular}{lcrrrrrrrrr}
\hline & \multicolumn{7}{c}{ Country/educational system } \\
\cline { 2 - 10 } Year & BFL & BFR & FRA & GRE & JPN & LUX & NET & SWI & U.S.A. \\
\hline First year & 84 & 84 & 85 & 88 & 87 & 83 & 84 & 87 & 83 & 7 \\
1985 & $*$ & 3 & 6 & 0 & 0 & 10 & 6 & 0 & 10 & 12 \\
1986 & $*$ & 5 & 8 & 0 & 0 & 14 & 8 & 2 & 15 \\
1987 & $*$ & 7 & 10 & 0 & 1 & 15 & 10 & 6 & 7 \\
1988 & $*$ & 10 & 12 & 0 & 3 & 16 & 13 & 7 & 18 \\
1989 & 12 & 12 & 15 & 8 & 7 & 16 & 18 & 9 & 18 \\
1990 & 13 & 15 & 17 & 8 & 9 & 31 & 19 & 11 & 21 \\
$\%$ using schools (1989) & 78 & 93 & 99 & 5 & 36 & 100 & 87 & 74 & 100 \\
\hline
\end{tabular}

*Data not collected; 1985-1988, recall; 1989, actual; 1990, projected.

BFL: Belgium-Flemish; BFR: Belgium-French; FRA: France; GRE: Greece; JPN: Japan; LUX: Luxembourg; NET: The Netherlands; SWI: Switzerland. 


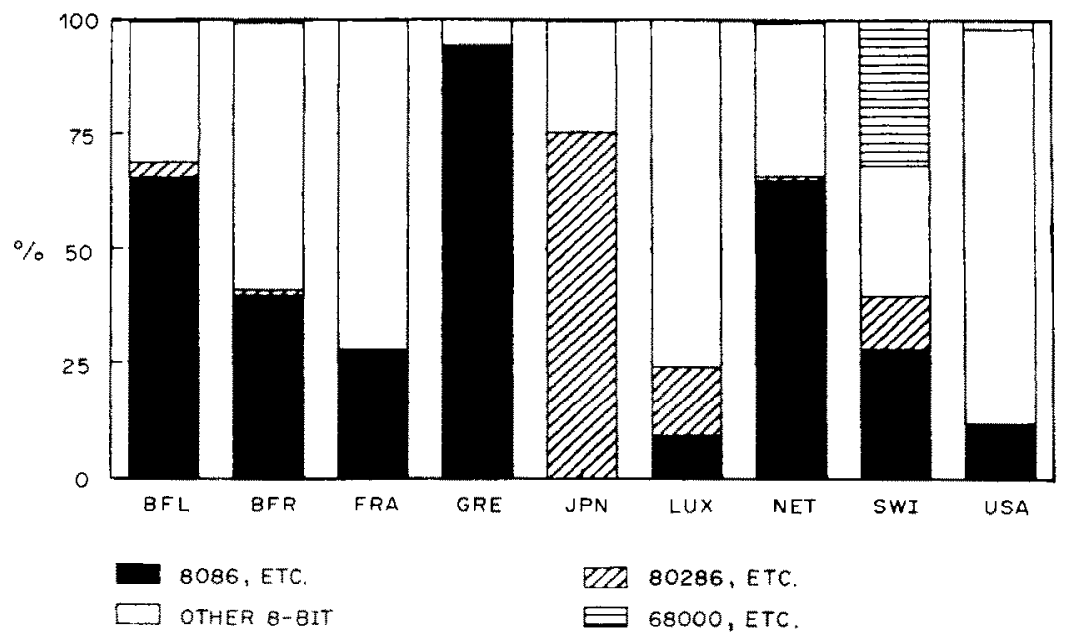

Fig. 1. Distribution of processor types.

The number of computers in a school conditions the way computers can be used in the teaching/learning process. From Table 3 we see that in 1985 in the U.S.A. the average number of computers in lower secondary schools was 11 , a level reached by many other countries in 1988 or 1989.

On class-level, the computer: student ratio determines whether whole class activities for certain applications are possible. Although opinions differ somewhat, a ratio of $1: 2$ is generally accepted as a sufficient condition for using computers in whole-class activities. Table 3 shows that in many educational systems, on the average, the number of available computers is only large enough to have one class at a time using computers. This means that at present, there are not many possibilities for using computers on a frequent basis throughout the school curriculum. How frequent can be illustrated with an example based on the computer:student ratio. For a school of 1500 students with 20 computers in a computer lab (assuming a class-size of 25 students and 35 lesson periods of $50 \mathrm{~min}$ per week and an acceptable computer: student ratio of $1: 2.5$ ) the maximum access-time per week per class would be roughly 1.2 lesson periods for all possible activities.

Beside the number of computers in a school, the quality of the available hardware is another important factor influencing the potential computer use in a school. A simple indication can be obtained by looking at the type of machines that are available in schools. Each participating school was asked to list the type/brand of each available computer and the number of these in the school. The type/brand was coded according to the following scheme:

1 IBM 8086, etc.

2 Z-80, etc.

3 other 8 -bit process.

4 IBM 80286, etc.

5 Motorola 68000

6 IBM 80386, etc.

7 Motorola $68000+$, etc

8 other process types

Categories 1-3 include 8-bit machines, while categories 4-7 include the more up-to-date machines.

The data indicate (see Fig. 1) that in the European countries Belgium, Greece and The Netherlands IBM-compatible systems dominate, in France, Luxembourg and the U.S.A. other 8-bit machines. The relatively large amount of other 8 -bit processors in the U.S.A. $(>80 \%)$ mainly consist of Apple-II computers.

Another indication of the quality of the available hardware can be obtained by looking at the problems reported by the respondents with respect to hardware. It appears that the lack of availability of hardware (computers as well as peripherals), and the limitations of computers are still experienced as serious problems by a majority of principals and computer coordinators. 
Table 4. Availability in schools of different types of software (according to computer co-ordinators). Data are percent of schools in each country/system possessing each type of software

\begin{tabular}{lrrrrrrrr}
\hline & \multicolumn{7}{c}{ Country/educational system* } \\
\cline { 2 - 8 } Type of software & BFL & BFR & FRA & GRE & JPN & NET & SWI & U.S.A. \\
\hline Drill and practice & 52 & 64 & 96 & 6 & 60 & 72 & 53 & 93 \\
Tutorial programs & 47 & 31 & 47 & 14 & 33 & 80 & 46 & 78 \\
Word processing & 88 & 77 & 91 & 84 & 66 & 98 & 97 & 91 \\
Painting or drawing programs & 25 & 29 & 70 & 9 & 70 & 62 & 79 & 45 \\
Music composition programs & 4 & 6 & 37 & 5 & 9 & 7 & 30 & 24 \\
Simulation programs & 23 & 16 & 32 & 2 & 35 & 58 & 21 & 52 \\
Recreational games & 22 & 31 & 59 & 23 & 25 & 60 & 62 & 67 \\
Educational games & 27 & 37 & 78 & 9 & 22 & 70 & 38 & 93 \\
Programming languages & 78 & 67 & 77 & 86 & 61 & 67 & 80 & 42 \\
Spreadsheet programs & 75 & 51 & 72 & 66 & 63 & 92 & 87 & 55 \\
Mathematical graphing programs & 41 & 39 & 52 & 8 & 25 & 74 & 33 & 36 \\
Statistical programs & 18 & 17 & 24 & 6 & 38 & 48 & 17 & 15 \\
Database programs & 74 & 46 & 55 & 77 & 55 & 92 & 81 & 56 \\
Item banks & 3 & 2 & 6 & 3 & 7 & 31 & 4 & 22 \\
Recordiscore tests & 6 & 3 & 7 & 13 & 14 & 26 & 9 & 33 \\
Gradebook programs & 23 & 4 & 28 & 2 & 79 & 42 & 19 & 62 \\
Computer communication programs & 12 & 9 & 8 & 3 & 11 & 24 & 11 & 12 \\
Tools and utilities & 37 & 19 & 46 & 28 & 32 & 57 & 36 & 42 \\
\hline
\end{tabular}

*For abbreviations see Table 3 .

\section{Software}

The availability of software is a necessary condition for working with computers. An important distinction with respect to types of software is between generic software (like word processors, spreadsheets and database programs) that can be used in different contexts, and software designed for use in certain subject areas. The last type of software is especially important for enabling the use of computers in existing subjects. From the availability of different types of software in Table 4, we conclude that generic software is broadly available in more than $70 \%$ of computer-using schools for most countries.

Table 5 shows the availability in schools of software to be used in existing subjects. In most countries software is available for computer education in at least $60 \%$ of the schools.

There are many differences between countries in the availability of software for existing subjects. Especially in France and The Netherlands, many schools do have educational software available for subject areas like mathematics, science, mother tongue, foreign languages and social studies.

However, the data in Table 6 show that broad availability of software is absolutely no guarantee for a broad use of computers for instructional purposes by teachers. The figures for countries other

Table 5. Availability of software for different subjects (according to computer coordinator).

Data are percent of schools in each country/system possessing software in each subject area

\begin{tabular}{lrrrrrrrrr}
\hline & \multicolumn{7}{c}{ Country/educational system* } \\
\cline { 2 - 9 } Subject & BFL & BFR & FRA & GRE & JPN & LUX & NET & SWI \\
\hline Informatics & 92 & 69 & 71 & 66 & 27 & 78 & 91 & 72 \\
Mathematics & 52 & 54 & 93 & 10 & 66 & 63 & 89 & 51 \\
Science & 28 & 24 & 81 & 2 & 60 & 37 & 80 & 29 \\
Mother longue & 24 & 37 & 91 & 2 & 27 & 4 & 85 & 23 \\
Foreign languages & 43 & 20 & 81 & 2 & 39 & 4 & 75 & 24 \\
Creative arts & 2 & 4 & 57 & 2 & 12 & 0 & 38 & 13 \\
Social studies & 8 & 14 & 67 & 0 & 30 & 7 & 79 & 15 \\
Commercial studies & 35 & 29 & 31 & 2 & 0 & 37 & 59 & 30 \\
Technology (general) & 14 & 5 & 62 & 0 & 32 & 0 & 10 & 0 \\
Technical courses & 20 & 15 & 32 & 0 & 0 & 7 & 20 & 3 \\
Home economics & 4 & 0 & 14 & 0 & 14 & 0 & 3 & 1 \\
\hline
\end{tabular}

"For abbreviations see Table 3.

\begin{tabular}{|c|c|c|c|c|c|}
\hline & \multicolumn{5}{|c|}{ Country/educational system* } \\
\hline & BFL & LUX & NET & SWI & U.S.A. \\
\hline Mathematics & 8 & 8 & 14 & 21 & 56 \\
\hline Science & 4 & - & 4 & 15 & 39 \\
\hline Mother tongue & 3 & 7 & 8 & 11 & 44 \\
\hline
\end{tabular}

*For abbreviations see Table 3 . 
Table 7. Software problems in population 11 (according to the computer coordinators). Data are percent of schools in each country/system reporting problems

\begin{tabular}{|c|c|c|c|c|c|c|c|c|c|}
\hline \multirow[b]{2}{*}{ Problem } & \multicolumn{9}{|c|}{ Country/educational system* } \\
\hline & BFL & BFR & FRA & GRE & JPN & LUX & NET & SWI & U.S.A. \\
\hline Not enough software for instruction & 66 & 66 & 53 & 82 & 98 & 85 & 73 & 53 & 52 \\
\hline Software too difficult & 4 & 8 & 29 & 11 & 56 & 0 & $4 !$ & 14 & 3 \\
\hline Software not adaptable enough & 37 & 25 & 49 & 37 & 78 & 26 & 42 & 27 & 22 \\
\hline Poor quality of manuals & 17 & 23 & 32 & 65 & 62 & 11 & 16 & 27 & 14 \\
\hline Lack of information about software & 19 & 46 & 64 & 63 & 84 & 26 & 29 & 27 & 14 \\
\hline Soliwate not in instruction language & 17 & 25 & 3 & 70 & 22 & 26 & 10 & 14 & 0 \\
\hline
\end{tabular}

* For abbreviations see Table 3.

than the U.S.A., are low. Becker [4] obtained in his 1985 survey for the U.S.A. results similar to the present ones in Europe: an average of $12 \%$ of the teachers were using computers. Knowing that many countries, other than the U.S.A., started later to use computers in schools, the results of the repeated survey in 1992 will be of special interest for investigating whether in these countries the same development will have taken place as in the U.S.A. between 1985 and 1989.

This study did not record how many, and which programs are available in the schools, nor whether there is any shortage of particular software or what the quality of the available software is. There are some indicators that can throw some light on these questions. These indicators consist of the inventory of problems that were presented to the respondents with the request to indicate which problems with respect to software were experienced as serious in using computers. Table 7 shows that the shortage of software is experienced as an especial problem by most respondents, while the lack of information about software is another important problem in most countries. This is consistent with the priorities for computer-related expenditures mentioned by computer co-ordinators: (1) greater variety of instructional software, and (2) more tool software, while hardware wishes are next in priority: (3) more computers in laboratory settings, and (4) more printers and other peripherals.

\section{History and experience of schools with computers}

It has been often emphasized that the introduction of computers in education is a very complex innovation that requires the fulfilment of a large number of conditions before any success can be expected. One may argue that the introduction of computers is a matter of time; that schools need time to build up enough expertise, knowledge and experience of teachers before any impact might be expected. Therefore, it is important to look at the experience that schools have gained. One indicator of experience is the number of years schools have been using computers. Figure 2 shows that great variation exists within as well as between countries.

National stimulation policies in some countries started only recently resulting in limited years of experience; for example, in Greece a limited number of schools is participating in a national project, resulting in a median of $2 \mathrm{yr}$ experience for those schools.

There is a difference between countries in the driving forces behind the first computer use on school level. From Table 8 we infer that in some countries (Japan, The Netherlands and Switzerland) teachers were mostly the most important force, while in other countries (such as U.S.A., Luxembourg, Greece and Belgium-Flemish) this was the authorities, either outside the school or the school authorities. According to the principals, parents and local business and industry were not important driving forces.

The most important reasons for schools to introduce computers are depicited in Table 9 . These reasons are expressing only global goals, and offer as such no direct guidance for educational objectives or certain applications.

Schools were asked whether they have a written policy on the use of computers in the school. From Table 10 we conclude that in most countries only a minority of the computer using schools do have such a written policy. The exceptions are Greece, where the computer-using schools all participate in a special project of the government, and Luxembourg, where $13 \%$ of the 27 secondary schools report having a written policy.

Our data show that. in the countries discussed. financial support to schools is predominantly provided by national and local or regional authorities; parents and local business and industry 


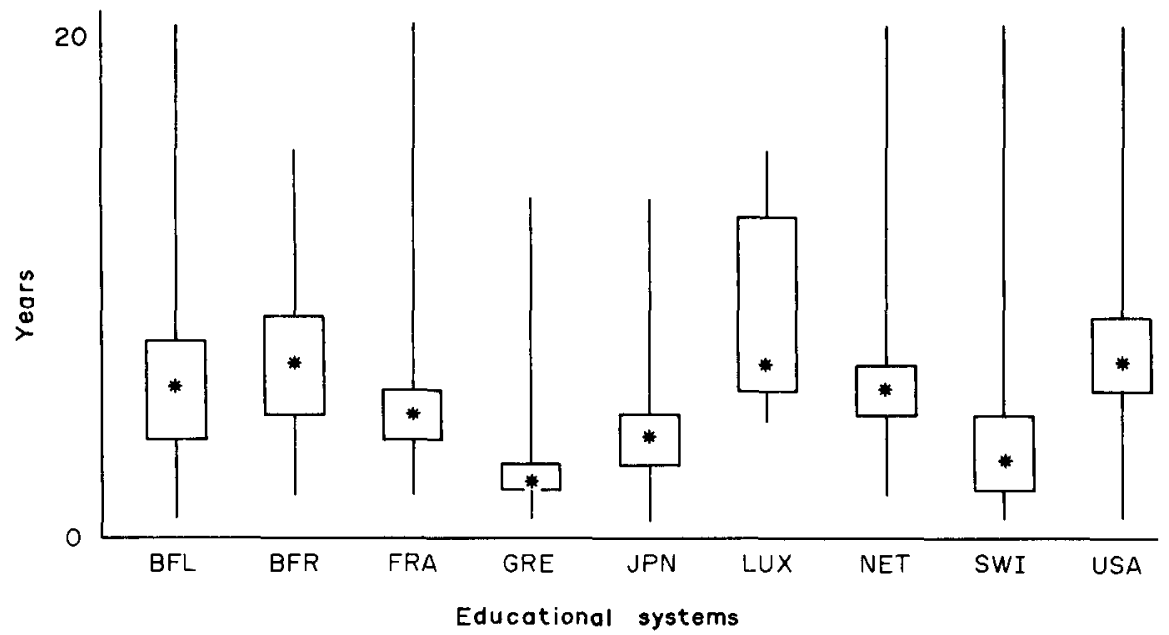

Fig. 2. Boxplots (boxes contain $25-75 \%$ of respondents, $*=$ median) of years of experience with computers of junior secondary schools according to principals.

hardly play a role. Further, neither universities nor teacher associations are playing a major role in teacher inservice training or other kinds of instructional support (the highest percentages reported are: in the U.S.A. $30 \%$ of the schools report support for inservice training; in Belgium-French and Luxembourg about $22 \%$ of the schools report some support).

\section{Attitudes of principals towards computers}

From the data gathered in the survey so far, it may be inferred that attitudes towards computers are a potent factor in determining the implementation of computers in schools. The attitudes of principals are of particular interest, as principals are major agents of change in a school. In this study attitudes of principals were measured by presenting them with a list of 15 attitude items. In the construction of this list three dimensions were distinguished, namely (1) Perceived Educational Impact, (2) Perceived Social Impact and (3) Training Needs. In order to explore whether these

Table 8. Most important driving force behind first introduction of computers in the schools (according to principals). Data are percent of schools in each country/system identifying particular driving forces

\begin{tabular}{|c|c|c|c|c|c|c|c|c|c|}
\hline \multirow[b]{2}{*}{ Driving force } & \multicolumn{9}{|c|}{ Country/educational system* } \\
\hline & BFL & BFR & FRA & GRE & JPN & LUX & NET & SWI & U.S.A. \\
\hline Outside authorities & 11 & 8 & 49 & 55 & 32 & 74 & 10 & 38 & 27 \\
\hline School authorities & 70 & 51 & 53 & 37 & 14 & 26 & 47 & 32 & 62 \\
\hline Particular department & 10 & 8 & 6 & 2 & 30 & 0 & 13 & 10 & 8 \\
\hline Group of teachers & 36 & 45 & 45 & 13 & 49 & 22 & 44 & 35 & 12 \\
\hline Individual teacher & 19 & 24 & 12 & 20 & 29 & 7 & 22 & 28 & 15 \\
\hline Parents & 1 & 2 & 1 & 6 & 0 & 0 & 1 & 0 & 8 \\
\hline Industry & 1 & 1 & 0 & 0 & 0 & 0 & 2 & l & 0 \\
\hline Students & 0 & 0 & 1 & 0 & 0 & 0 & 0 & 2 & 0 \\
\hline Other & 5 & 9 & 5 & 5 & 0 & 0 & 0 & 1 & 3 \\
\hline Do not know & 1 & 4 & 3 & 2 & 0 & 0 & 3 & 0 & 6 \\
\hline
\end{tabular}

*For abbreviations see Table 3 .

Table 9. Reasons for introducing computers in the school (according to principals). Data are percent of schools in each country/system identifying particular reasons

\begin{tabular}{|c|c|c|c|c|c|c|c|c|c|}
\hline \multirow[b]{2}{*}{ Reasons } & \multicolumn{9}{|c|}{ Country/educational system* } \\
\hline & BFL & BFR & FRA & GRE & JPN & LUX & NET & SWI & U.S.A. \\
\hline Give students experience for future & 98 & 99 & 84 & 98 & 87 & 96 & 99 & 95 & 86 \\
\hline Make school more interesting & 76 & 79 & 71 & 56 & 70 & 64 & 63 & 36 & 58 \\
\hline Attract students to the school & 37 & 57 & 11 & 9 & 39 & 5 & 36 & 7 & 15 \\
\hline Improve student achievement & 64 & 78 & 70 & 45 & 66 & 57 & 58 & 23 & 76 \\
\hline Keep curriculum methods up-to-date & 85 & 83 & 42 & 84 & 76 & 45 & 71 & 53 & 89 \\
\hline Promote individualized learning & 56 & 71 & 76 & 53 & 83 & 50 & 55 & 52 & 67 \\
\hline Promote cooperative learning & 44 & 54 & 51 & 75 & 53 & 47 & 26 & 34 & 48 \\
\hline School had opportunity to acquire & 46 & 52 & 62 & 67 & 80 & 43 & 49 & 34 & 39 \\
\hline Teachers were interested & 88 & 85 & 60 & 72 & 72 & 72 & 90 & 81 & 59 \\
\hline
\end{tabular}

*For abbreviations see Table 3. 
Table 10. School policies with respect to computer use (according to principals). Data are percent of schools in each country/system identifying particular policies or having a written policy

\begin{tabular}{lccccccccc}
\hline & \multicolumn{7}{c}{ Country/educational system* } \\
Policies & BFL & BFR & FRA & GRE & JPN & LUX & NET & SWI & U.S.A. \\
\hline Computer experience before graduation & 83 & 35 & 68 & 84 & 20 & 85 & 98 & 65 & 63 \\
Content of introduction course & 68 & 62 & 41 & 79 & 10 & 96 & 75 & 81 & 62 \\
Instruction with computers & 53 & 42 & 39 & 58 & 13 & 93 & 62 & 51 & 26 \\
Content of computer science course & 76 & 71 & 37 & 74 & 7 & 92 & 81 & 74 & 48 \\
Computer game playing rules & 11 & 7 & 10 & 6 & 5 & 0 & 47 & 12 & 33 \\
Priorities of instructional uses & 57 & 31 & 36 & 22 & 10 & 7 & 61 & 26 & 20 \\
Actions to ensure equity & 51 & 12 & 7 & 29 & 5 & 4 & 66 & 18 & 15 \\
Prescribe computer use in grades & 79 & 58 & 50 & 59 & 17 & 89 & 90 & 50 & 24 \\
Prescribe soft-and or hardware & 67 & 44 & 51 & 50 & 22 & 92 & 64 & 65 & 42 \\
Written policy on computer use & 9 & 20 & 32 & 86 & 13 & 48 & 27 & 29 & 27 \\
\hline
\end{tabular}

*For abbreviations see Table 3.

dimensions are present in the data, the attitude data of all principals across countries were analyzed with principal component analysis; the results are depicted in Fig. 3.

The results indicate that, in general, principals from schools that are using computers have more favourable attitudes towards the impact of computers and training than principals from schools not using computers. Although this result seems plausible as far as innovation theory is concerned, it would be too early to infer a causal link at this moment, and more detailed analyses are needed for investigating the nature of this seemingly interesting relation.

The results of the breakdown by years of experience are also interesting, indicating that the more experience schools have, the more positive principals are about the impact of computers, be it educational or social. At the same time the need for training as expressed by principals seems to be inversely related to the number of years the school has experience with computers: the shorter the experience of the schools with computers is, the more principals express a need for training. The result suggests an interesting hypothesis which should be further explored, namely that an active policy and external support, for example directed at teacher training, over a number of years is necessary to get a change institutionalized.

\section{Contexts: learning about computers}

As we saw before, one of the major objectives for using computers in schools is to teach students to become acquainted with this new technology. Here we present only some of the results about the context in which learning about computers takes place.

In many countries discussions are taking place about the context in which students should learn about computers. One approach is that students will learn about computers while using them in

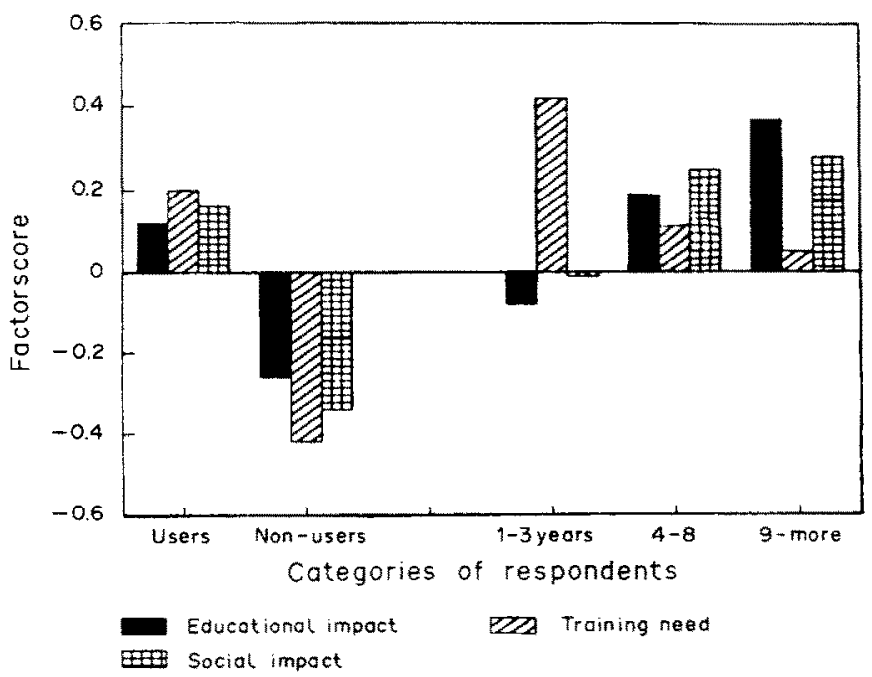

Fig. 3. Attitudes of principals towards computers (scores on factors). 
Table 11. (A) Contexts in which students receive a significant amount of computer education and (B) contexts in which students receive most computer education. Data are percent of schools in each country/system identifying particular sources of computer education

\begin{tabular}{|c|c|c|c|c|c|c|c|c|c|}
\hline & \multicolumn{9}{|c|}{ Country/educational system* } \\
\hline & BFL & BFR & FRA & GRE & IPN & LUX & NET & SWI & U.S.A. \\
\hline \multicolumn{10}{|c|}{$\begin{array}{l}\text { (A) Subject with substantial } \\
\text { amount of computer } \\
\text { instruction }\end{array}$} \\
\hline Separate course & 84 & 93 & 38 & 100 & 20 & 100 & 92 & 91 & 64 \\
\hline Mathematics & 11 & 13 & 33 & 8 & 15 & 0 & 14 & 31 & 34 \\
\hline Science & 2 & 2 & 6 & 0 & 7 & 0 & 8 & 8 & 12 \\
\hline Mother tongue & 2 & 3 & 10 & 0 & 1 & 4 & 4 & 9 & 21 \\
\hline Foreign language & 5 & 0 & 5 & 2 & 2 & 0 & 2 & 3 & 3 \\
\hline Creative arts & 0 & 1 & 2 & 0 & 2 & 0 & 3 & 1 & 2 \\
\hline Social studies & 0 & 2 & 2 & 0 & 2 & 0 & 5 & 2 & 6 \\
\hline Commercial studies & 5 & 15 & 8 & 0 & 0 & 22 & 6 & 10 & 13 \\
\hline Technology, general & 11 & 4 & 55 & 0 & 17 & 0 & 4 & 1 & 0 \\
\hline Technology, specific & 5 & 11 & 15 & 0 & 0 & 15 & 11 & $i$ & 7 \\
\hline Home economics & 1 & 0 & 2 & 0 & 1 & 0 & 0 & 1 & 3 \\
\hline Informal instruction & 7 & 5 & 22 & 0 & 0 & 0 & 2 & 1 & 9 \\
\hline \multicolumn{10}{|l|}{$\begin{array}{l}\text { (B) Subject with most } \\
\text { computer instruction }\end{array}$} \\
\hline Separate course & 87 & 90 & 10 & 100 & 24 & 93 & 91 & 90 & 51 \\
\hline Mathematics & 4 & 0 & 13 & 0 & 36 & 0 & 1 & 6 & 13 \\
\hline Science & 0 & 2 & 2 & 0 & 9 & 0 & $i$ & 0 & 2 \\
\hline Mother tongue & 0 & 0 & 2 & 0 & 0 & 0 & 1 & 1 & 6 \\
\hline Forcign language & 2 & 0 & 1 & 0 & 1 & 0 & 0 & 0 & 0 \\
\hline Creative arts & 0 & 0 & 0 & 0 & 0 & 0 & 0 & 0 & 0 \\
\hline Social studies & 0 & 0 & 1 & 0 & 1 & 0 & 0 & 0 & 0 \\
\hline Commercial studies & 0 & 3 & 1 & 0 & 0 & 7 & 1 & 0 & 4 \\
\hline Technology, general & 4 & 2 & 54 & 0 & 29 & 0 & 0 & 0 & 0 \\
\hline Technology, specific & 1 & 0 & 5 & 0 & 0 & 0 & 1 & 0 & 0 \\
\hline Home economics & 0 & 0 & 1 & 0 & 0 & 0 & 0 & 0 & 0 \\
\hline Informal instruction & 2 & 0 & 7 & 0 & 0 & 0 & 0 & 1 & 1 \\
\hline
\end{tabular}

* For abbreviations see Table 3 .

existing subjects. Another approach is to have (often next to computer use in existing subjects) a separate course that only addresses the learning about computers and information handling.

Table 11 (part A) shows all contexts in which students learn a significant amount about computers, while part B depicts the context in which most of this learning takes place.

The data clearly show that in most countries learning about computers takes place in a separate subject. An exception is France where the context for receiving instruction about computers is mainly general technology. In many countries part of the mathematics lessons is devoted to learning about computers. All teachers in the sample (computer education teachers as well as teachers in existing subjects) have been asked to indicate which computer-related topics they teach, for later analysis.

\section{CONCLUDING REMARKS}

The results presented in this paper show that the process of introducing computers into education is, despite all stimulation policies at national, state, regional and local level, still in its early stages. Almost all secondary schools do possess computers and are using them for instructional purposes. At the same time, we must conclude that, on the average, only a small number of teachers of existing subjects are computer users, and that the types of computer use in schools are still unsophisticated.

If we interpret our data in relation to the important factors which influence educational change, we may conclude that in general the conditions in which these factors operate are not yet completely established. Government-developed stimulation policies may be successful as such, but not sufficient to fulfil the stringent conditions which operate at school level: resources (hardware as well as software) are still too limited, teachers report time problems, students have limited access to computers, staff development is reported as a problem, especially for schools just starting.

We do not believe that this is a disappointing situation. Effective integration of computers in education is a complex process, and Walker [5] rightly points to the need for new patterns of schooling that will require collaborative effort on a large scale sustained over a decade or more. 
Since the majority of the surveyed schools have only been using computers for a few years, their policies in most cases are not spelled out. This situation reflects the typical characteristics of an early stage of implementation. In due course, schools will turn their activities into purposeful implementation policies.

\section{REFERENCES}

1. Fullan M., The Meaning of Educational Change. Teachers College Press, Columbia University, New York (1982).

2. Fullan M., Miles M. B. and Anderson S. E., Strategies for Implementing Microcomputers in Schools: The Ontario Case. Ontario Ministry of Education, Toronto (1986).

3. Pelgrum W. J. and Plomp $\mathrm{Tj}$., The Use of Computers in Education Worldwide: Results from the IEA 'Computers in Education' Survey in 19 Educational Systems. Pergamon Press, Oxford (1991).

4. Becker H. J., Instructional Uses of School Computers: Reports from the 1985 National Survey. Center for Social Organization of Schools, The Johns Hopkins University, Baltimore, Md (1986).

5. Walker D. F., Computers and the curriculum. In Microcomputers and Education (Edited by Culbertson J. A. and Cunningham L. L.), 85th NSSE yearbook, pp. 22-39. The University of Chicago Press, Chicago (1986). 